\title{
58. X-RADIOGRAPHY OF HOLE 480: PROCEDURES AND RESULTS ${ }^{1}$
}

\author{
A. Soutar, S. R. Johnson, and E. Taylor, ${ }^{2}$ Scripps Institution of Oceanography, La Jolla, California \\ and \\ T. R. Baumgartner, Centro de Investigación Cientifíca y de Educación Superior de Ensenada, Ensenada, Mexico
}

\section{INTRODUCTION}

Efficient access to information contained in laminated sediments is obtained by careful preparation, description, and curation of the core material. We describe the procedures, selected radiographic results with preliminary descriptions of structural variation, and, based on the physical stratigraphy, the estimated ages of the Site 480 HPC material.

\section{METHODOLOGY}

The standard shipboard procedure of subsampling the working halfcore was suspended for the Hole 480 cores. With the exception of two plug holes, all 31 cores were returned to the west coast repository for storage under standard conditions $\left(2-4^{\circ} \mathrm{C}\right.$ and variably high humidity)

An ad hoc subsampling committee decided on a general sampling policy, including preliminary surface scraping, continuous photography, complete X-radiography of halfcore sections, and the cutting and radiography of 1-cm-thick slabs from selected sections. What follows are the procedures for the radiography and slabbing work.

\section{Working Halfcore Procedure (Cores 1-31)}

1. Exposed sediment was scraped with a sharp blade to clean and prepare the surface for photography (Chase et al., this volume, $\mathrm{Pt}$. 1) and to provide subsamples for oxygen isotope and pollen studies.

2 . We placed reference marks on the core liners at 10 -cm intervals.

3. The entire halfcore was radiographed using overlapping exposures centered at each 10-cm reference mark. We took exposures on $8^{\prime \prime}$ $\times 10^{\prime \prime}$ Ready Pak Kodak XTL-2 film. Exposure time ranged from 3.5 to 4.0 minutes at 60 to $70 \mathrm{kv}$ accelerating voltage on a Faxitron instrument. Developing time for the film accorded with manufacturers' recommendations. The 152-meter section required about 600 individual exposures ( 2 exposures per film pack). We used 5 - and $10-\mathrm{cm}$ markers and a mask with lead letters to permanently identify the core number and section of the radiographs. (Note that the reference markers do not correspond to standard Deep Sea Drilling Project (DSDP) core depth notation.)

\section{Slabbing Procedure (Cores 1-15)}

1. We levelled and smoothed the core surface by cross-core scraping with a spatula blade. Smoothing uneven surfaces on 1-cm slabs avoids artifacts in the radiography. By the time the slabbing preparation was begun (July 1979), an additional scraping had occurred for other subsamples. The result was a distinctly concave core surface often with millimeter-size ridges. Mold began to appear, and we removed the surface expression with a final scraping.

2. Using a drawknife core liner cutter provided by $\mathrm{T}$. Walsh of the Scripps Institution, we cut the butyrate core liner lengthwise, $1 \mathrm{~cm}$ below the sediment surface. It was difficult to obtain an entirely satisfactory cut for the length of certain sections, because of the structural

\footnotetext{
${ }^{1}$ Curray, J. R., Moore, D. G., et al., Init. Repts. DSDP, 64: Washington (U.S. Govt. Printing Office).

2 Taylor's present address: Department of Oceanography, Texas A\&M University, College Station, Texas.
}

irregularity of the plastic liner, the uneven size of the shipboard cut, and the uneven level of the sediment surface. We achieved consistent depth control by cutting one side of the liner at a time.

3. As many as eight, $10-20$-cm-long, 1-cm-thick slabs were removed from Core 1 through part of Core 15. After removing the cut liner strips, we covered the exposed surface of the halfcore with a continuous sheet of polyethylene wrapping plastic. Slabs were then premarked and diagonal cuts in the plastic were made at separation points. The plastic associated with each slab was then individually folded and tucked on the sediment surface.

We then transferred the halfcore to a planer slab jig, consisting of two, $1-\mathrm{cm}$ offset vertical walls ( $1.5 \mathrm{~m}$ long and $8 \mathrm{~cm}$ high) separated by a $25-\mathrm{cm}$ articulated slab catcher tray. This arrangement allowed us to rotate the halfcore surface against the vertical wall support while exposing a $25-\mathrm{cm}$ section for slabbing.

Before rolling the core surface to the vertical, we used a finebladed saw to make a 1-cm-deep diagonal cut at each slab separation point. A stiff (20-mil PVC) plastic card was then folded into the polyethylene covering the core surface. This card became the slab's bottom support for subsequent operations and curation.

We then rolled the core to the vertical and raised the slab catcher tray snugly against the plastic card and wrap protecting the core surface. The catcher tray has $1-\mathrm{cm}$ sides projecting over the halfcore as guides for the wire; we used sawblade or monofilament to excise the slab from the halfcore. After the slab was cut, we rotated the catcher tray down with the slab. It was then flat on the counter top and freely accessible.

4. We trimmed each slab, marked one edge with stainless steel, color-coded reference pins, and placed the slabs in individually wrapped polyethylene/acrylic boxes for storage in modified D-tube holders in the DSDP refrigerator. If necessary, the newly exposed surface of the slab was smoothed and levelled to a thickness of $1 \mathrm{~cm}$. We trimmed the edge from the marker pin side $(1-2 \mathrm{~mm})$ and saved all trimmings in labelled plastic bags. Blue, plastic-head stainless steel pins were inserted to correspond to the $10-\mathrm{cm}$ reference marks, and red glass-head pins were inserted to indicate the top of the core slab.

Storage boxes (with a slab compartment $1.5 \mathrm{~cm}$ deep, $6.3 \mathrm{~cm}$ wide, and $21 \mathrm{~cm}$ long with symmetrical $3.5-\mathrm{cm}$-long moisture sponge compartments) were assembled from linear polyethylene and clear acrylic flat stock. We devised two methods of sealing: (1) heat shrink plastic tubing; and (2) multiple wrapping in polyethylene film. Because of convenience in handling, the latter was used exclusively. We cut standard DSDP D-tube-holders longitudinally to form shallow C-tubes. These hold five slab boxes each and fit in the standard storage racks.

5. Except for short slabs, each slab was X-rayed using two offset exposures per slab. The first exposure centered the top half on the beam, and the second centered the bottom half. We used a mask with lead letters to identify permanently the core number and section and the $5-$ and $10-\mathrm{cm}$ markers on the radiograph. These markers correspond to the markers in the set of radiographs of the core in the halfcore liner. The radiographs of the slabs were again taken by the Faxitron instrument using Kodak Ready Pak film. Exposures were 2.5 minutes at $65 \mathrm{kv}$.

\section{CURATORIAL NOTES}

We immediately covered the working halfcore with polyethylene film and have attempted to keep this film in place at all times. 
To control mold, the working and archive halfcores were sprayed with a dilute $(3 \%)$ formalin solution approximately seven months after collection, and the archive halfcore was covered with plastic film. We noticed a significant amount of mold on the working halfcore at the time the liners were cut (6 months after collection). To inhibit the spread of mold, we sprayed a $3 \%$-solution of formalin directly on the core surface so that the surface was thoroughly wetted. This was only partially effective; mold was found on some of the treated sections six months later. We also noted considerable mold (up to $50 \%$ ) on the archive halfcore, so the formalin spraying was extended to those cores. Formalin and propylene glycol (Steedman, 1976) should be applied at least once per year to control mold. After slabbing the individual core sections, we sprayed the remaining portion of the working halfcore with dilute formalin and covered it with polyethylene film.

\section{ESTIMATED EFFORT}

A partitioning of the estimated effort for the foregoing procedures and the following organizational activities is given in Table 1; about 2800 work hours were required for the project.

\section{RADIOGRAPHY RESULTS}

Each radiograph has been mounted in "Clear View" transparent protectors and filed sequentially in threering binders. The halfcore (Cores 1-31) and slab sequences (Cores 1-15) are filed separately. For each radiograph, we prepared a cartoon line drawing indicating the outline of the core and major structural-stratigraphic elements. The cartoons facilitate general access to the radiographs for observation and subsample selection. The radiographs are on file at the Scripps Institution.

To summarize the structural variability of the core as depicted on the radiographs, we developed a set of more-or-less commonly employed descriptive terms (Table 2). The terms are ordered to reflect the degree of preservation of original depositional structure relevant to the chronographic use of the record.

The sedimentary character of the Hole 480 core as displayed in the radiographs is presented in Figures 1A through $1 \mathrm{M}$. Table 2 gives a preliminary estimate of the percentage distribution of the various sediment structural types. We drew the distributions from the slab and

Table 1. Breakdown of effort involved in processing cores from Hole 480.

\begin{tabular}{lcrr}
\hline \multicolumn{1}{c}{ Job } & $\begin{array}{c}\text { Effective Core } \\
\text { Length }(\mathrm{m})\end{array}$ & $\begin{array}{c}\text { Work Hours } \\
\text { per Meter }\end{array}$ & $\begin{array}{r}\text { Total } \\
\text { Hours }\end{array}$ \\
\hline X-Ray Halfcores & 142.5 & 3.8 & 540 \\
Slab Cores & 61.7 & 17.5 & 1080 \\
X-Ray Slabs & 61.7 & 5.8 & 358 \\
General Curation & 346.7 & 0.2 & 69 \\
Organization & 204.2 & 0.2 & 41 \\
Cartoon Halfcore Radiographs & 142.5 & 2.5 & 356 \\
Cartoon Slab Radiographs & 61.7 & 5.8 & 358 \\
& & & 2802 \\
\hline
\end{tabular}

Table 2. Gross percentage occurrence of stratigraphic-structural types in slab and halfcore radiographs.

\begin{tabular}{lcc}
\hline Sediment Type & $\begin{array}{c}\text { Slab Radiographs } \\
0-71.5 \mathrm{~m} ; \mathrm{N}=250 \\
(\%)\end{array}$ & $\begin{array}{c}\text { Halfcore Radiographs } \\
0-152 \mathrm{~m} ; \mathrm{N}=225 \\
(\%)\end{array}$ \\
\hline Laminae & 35 & 15.5 \\
Faint Laminae & 3.5 & 30 \\
Complex Laminae & 5 & 2.5 \\
Disturbed Laminae & 7 & 8 \\
Layered & 1.5 & 1 \\
Faintly Layered & 1.5 & 5.5 \\
Motley Layered & 2 & 1 \\
Burrowed & 1.5 & 1.5 \\
Mottled & 21.5 & 1 \\
Faintly Mottled & 18.5 & 8.5 \\
Homogenous & 0 & 17.5 \\
Sand & 0 & 0.5 \\
Gray Layer & 0 & 0.5 \\
\hline
\end{tabular}

halfcore radiographs by random point sampling ( 250 and 225 samples, respectively).

Differences in sediment type occurrences are apparent between the halfcore and slab radiographs: for example, sand and gray layers appear in the halfcore but are not reached by slabbing. More substantial differences are apparent, particularly in the greater abundance of designated laminated sediments in the slab radiographs and the complementary greater abundance of faint laminae in the halfcore radiographs. Again, some of this effect may reflect the overall distribution and compaction in the entire core rather than the upper slabbed region; but much of the difference arises from the higher resolution of fine structure in the X-radiographs obtained from the slabs. This effect is also reflected in the mottled-versus-homogenous designation on the radiographs. In the halfcore descriptions, a homogenous designation for sediment structure is quite common; but the slab radiographs reveal complexities of structure obscured by the uneven and thicker halfcore section.

\section{PRELIMINARY ESTIMATE OF CORE CHRONOLOGY}

We also sampled laminae couplet (varve) counts per centimeter at appropriate positions during the random point sampling ( 96 counts/slab and 86 counts/halfcore radiographs). The mean of the slab counts is 10.4 per $\mathrm{cm}$ with a standard deviation of 3.6. The mean of the halfcore counts is 14.8 per $\mathrm{cm}$ with a standard deviation of 5.3 .

We made projected age estimates by assigning time intervals to the various sediment types and then used the downcore quantities of each type as chronostratigraphic estimators. The time interval represented by a particular sediment type is as follows:

$$
t_{s}=L_{s} \cdot r_{s} \cdot v \cdot d_{s},
$$

where $t_{s}$ is the time interval, $L_{s}$ is the length of section of a particular sediment type, $r_{s}$ is the ratio of the section length $L_{s}$ to the total core depth of interest, $d_{s}$ is the 
ratio of the density of a particular sediment type to the density of laminated sediment, and $v$ is the estimated number of varves per meter. The time interval is the summation of all the time intervals estimated for each of the designated sediment types as in Table 2 :

$$
t=t_{L}+t_{F L}+\ldots+t_{M}+t_{H}-t_{S}-t_{G L} .
$$

The most straightforward application of this technique is the time interval estimate for the laminated sections: The varve count, aside from a correction term to compensate for compaction, may be directly applied. Justification for using laminae pair counts as a measure of time in the Guaymas slope region can be found in the favorable comparison of such varve counts within the framework of $\mathrm{Pb}-210$ radiometric dating (Bruland, 1974; DeMaster, 1979). In this preliminary estimate, we assume that a general increase in varve concentration occurs such that, in Core 8 , the varve thickness is 0.8 that of Core 1, and, similarly, the varve thickness of Core 8 is 1.2 times that of Core 16 . We further assume no loss of sediment section (see Byrne, this volume, Pt. 2).

Mottled sediments represent the reworking of normal deposition, and we assume that no change in source or supply has occurred. Given this simplification, the only correction needed to estimate the time interval for nonlaminated sediments is one that will account for an increase of density. Shipboard density measurements suggest that homogeneous sediments are 1.2 times as dense as laminated sediments. Therefore, we assume a quasi-linear increase in density for the descending arrangement of sediment types given in Table 2 . As an example, the density of mottled sediment is taken as 1.15 times that of laminated sediment within the same core.

A further item of concern in estimating a chronology for the core is surface sediment recovery. An examina- tion of the few available water content values, as reported in the shipboard data, suggests values lower (about $1 \%$ ) than those encountered in the sediments on the very surface. This, coupled with the apparent $a b-$ sence of European pollen varieties in the uppermost sediment of Core 480 (see Byrne, this volume, Pt. 2), leads to the tenuous assumption that the record begins approximately 450 years ago.

A preliminary chronology of Hole 480 , based on the effort thus described, is given in Figure 2. The ages at the base of Cores 1 to 22 are estimated. As a first approximation, the age estimates and general changes in sediment character are not inconsistent with glaciation history as depicted by the Greenland ice core chronography (Dansgaard et al., 1971). Applying the time summation procedure over the entire core provides a preliminary estimate of about 210,000 years before the present to the bottom of the Hole 480 section.

\section{ACKNOWLEDGMENTS}

The authors gratefully note the help of David G. Moore in providing support and opening DSDP doors. We also gratefully acknowledge the voluntary help of Garvin and Jon Soutar in preparing the radiograph cartoons.

\section{REFERENCES}

Bruland, K. W., 1974. Lead-210 geochronologies in the coastal marine environment [Ph.D. dissert.]. University of California, San Diego.

Dansgaard, W., Johnsen, S. J., Clausen, H. B. et al., 1971. Climatic record revealed by the Camp Century ice core. In Turekian, K. K. (Ed.), Late Cenozoic Glacial Ages: New Haven (Yale University Press), pp. 37-56.

DeMaster, D. J., 1979. Marine budgets of silica and silicon 32 [Ph.D. Dissert.]. Yale University.

Steedman, H. F., 1976. Miscellaneous preservation techniques. In Steedman, H. F. (Ed.), Zooplankton Fixation and Preservation: Paris (UNESCO), pp. 175-181. 


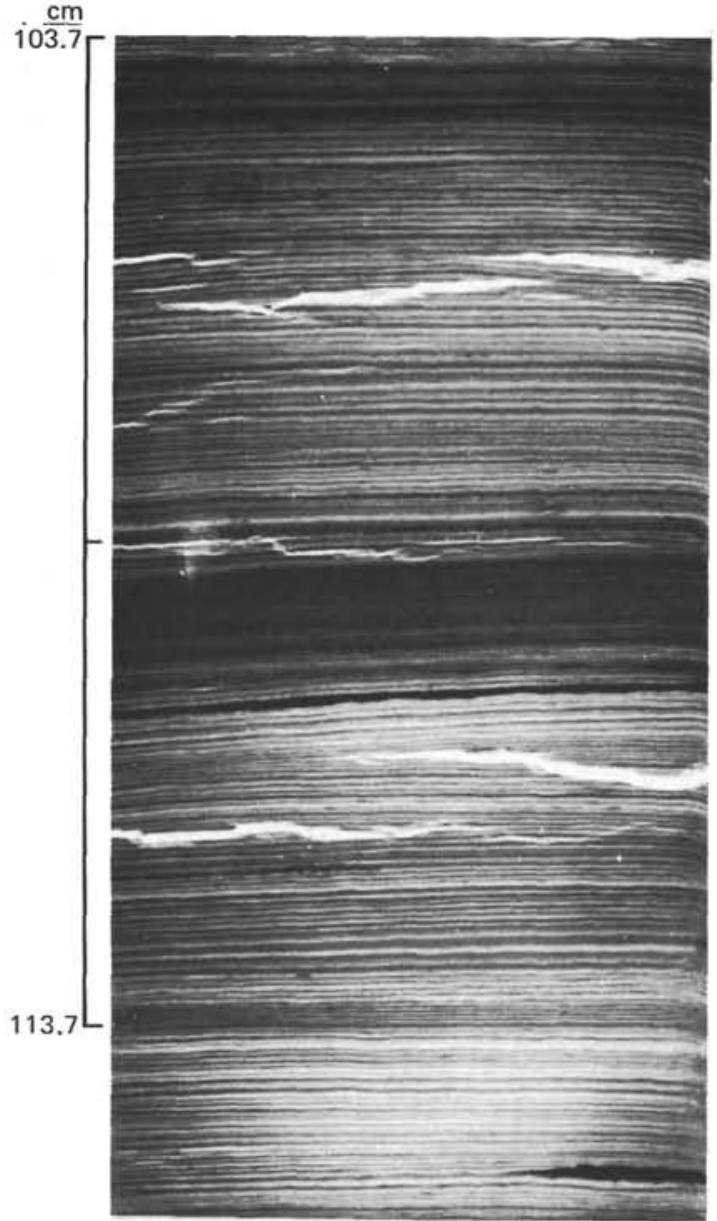

Figure 1A. Slab radiograph, 480-14-1, 103.7-115.7 cm. Laminae: well-developed and consistent laminations from submillimeter to $2.0-\mathrm{mm}$ scale.

${ }^{3}$ NOTE: This and all subsequent figures are positive prints from original radiographs; thus, the darker the tone the denser the sediment.

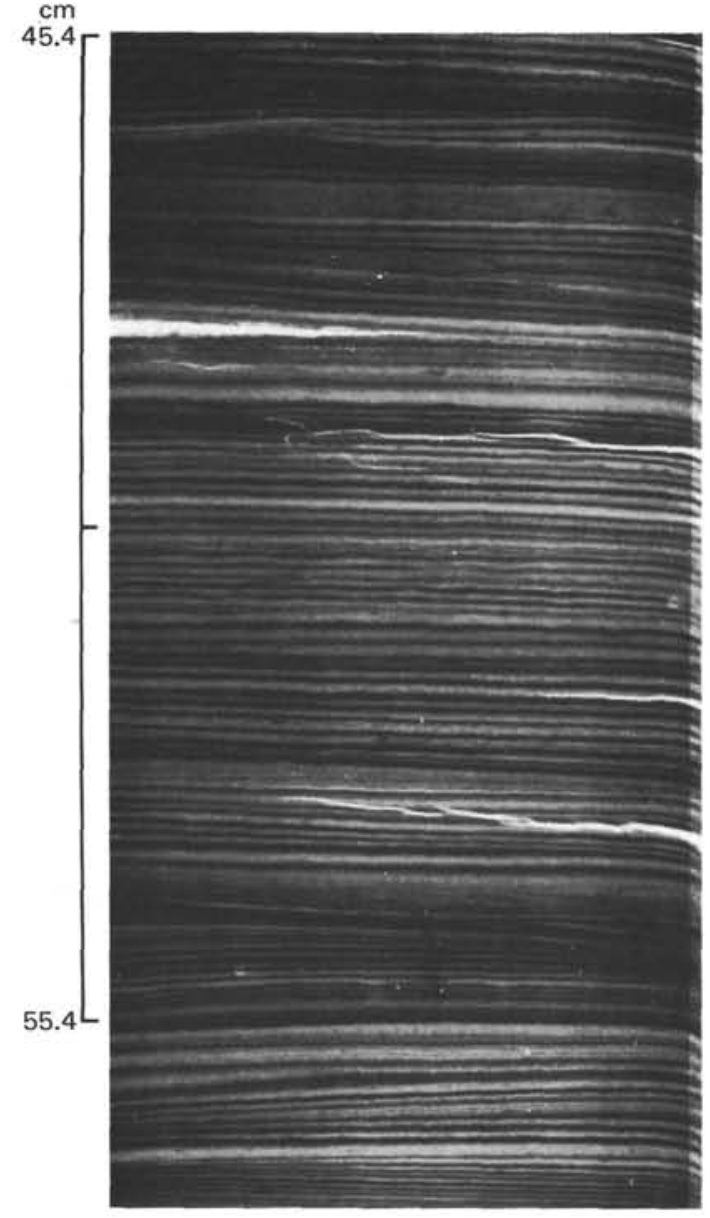

Figure 1B. Slab radiograph, 480-10-2, 45.4-57.4 cm. Laminae: well-developed laminations from submillimeter to $2.5-\mathrm{mm}$ scale; but even in the best-developed sequences, minor interruptions are the rule, not the exception (c.f., the record at $46.3,47$, and $54 \mathrm{~cm}$ ).

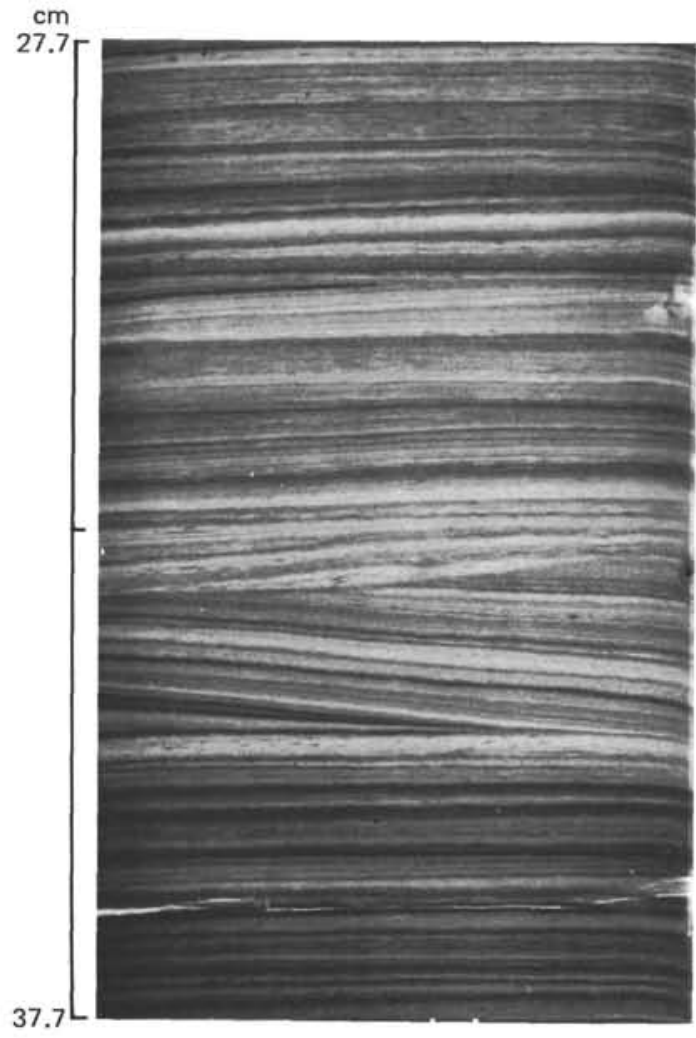

Figure 1C. Slab radiograph, 480-7-3, 27.7-37.7 cm. Complex laminae: well-developed laminated sequence with angular discontinuities at 33 and $35 \mathrm{~cm}$. 


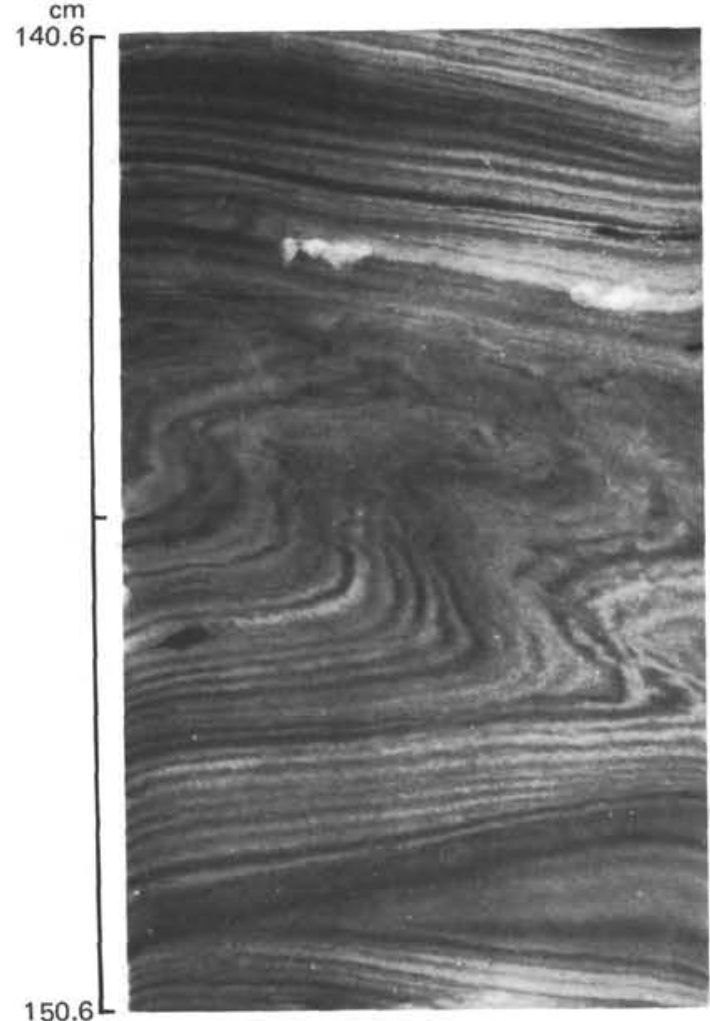

Figure 1D. Slab radiograph, 480-1-2, 140.6-150.6 cm. Complex laminae: rare occurrence of drag-flow-re-

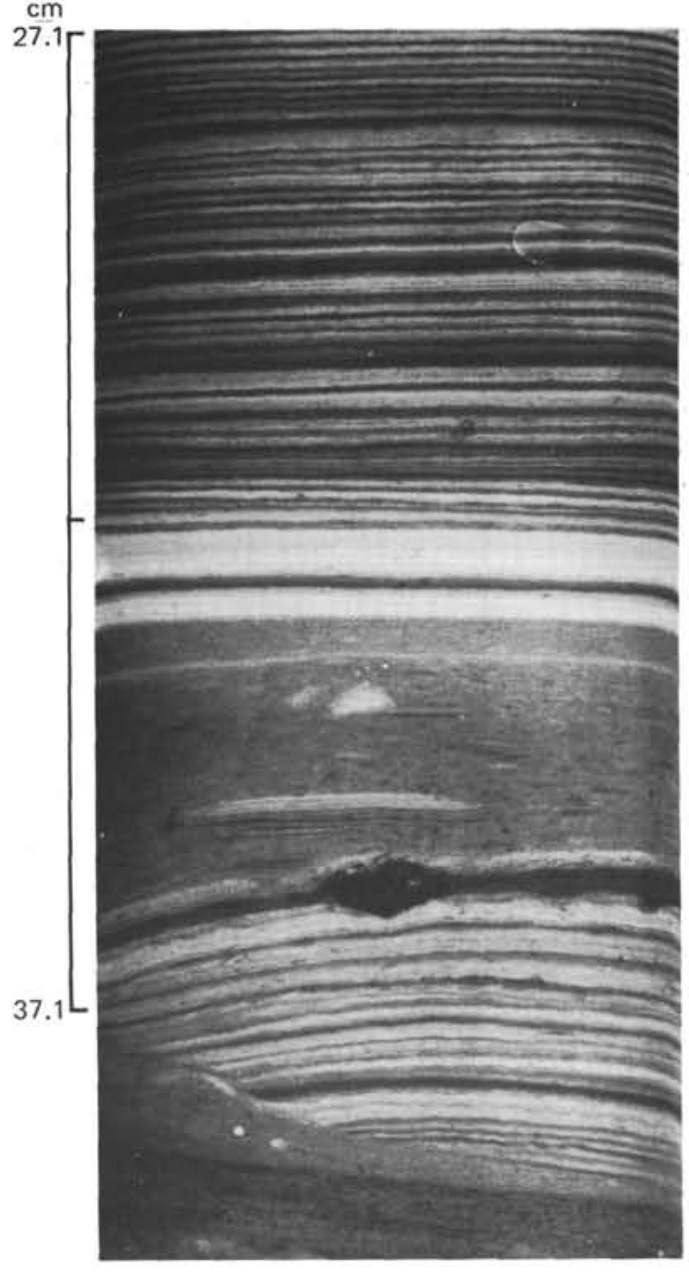

Figure 1E. Slab radiograph, 480-2-3, 27.1-39.5 cm. Dis turbed laminae: disturbed laminations showing relic whole laminated regions imbedded in a nonlaminated sequence $(33-36 \mathrm{~cm})$. A likely interpretation involves mass movement of bottom sediment.

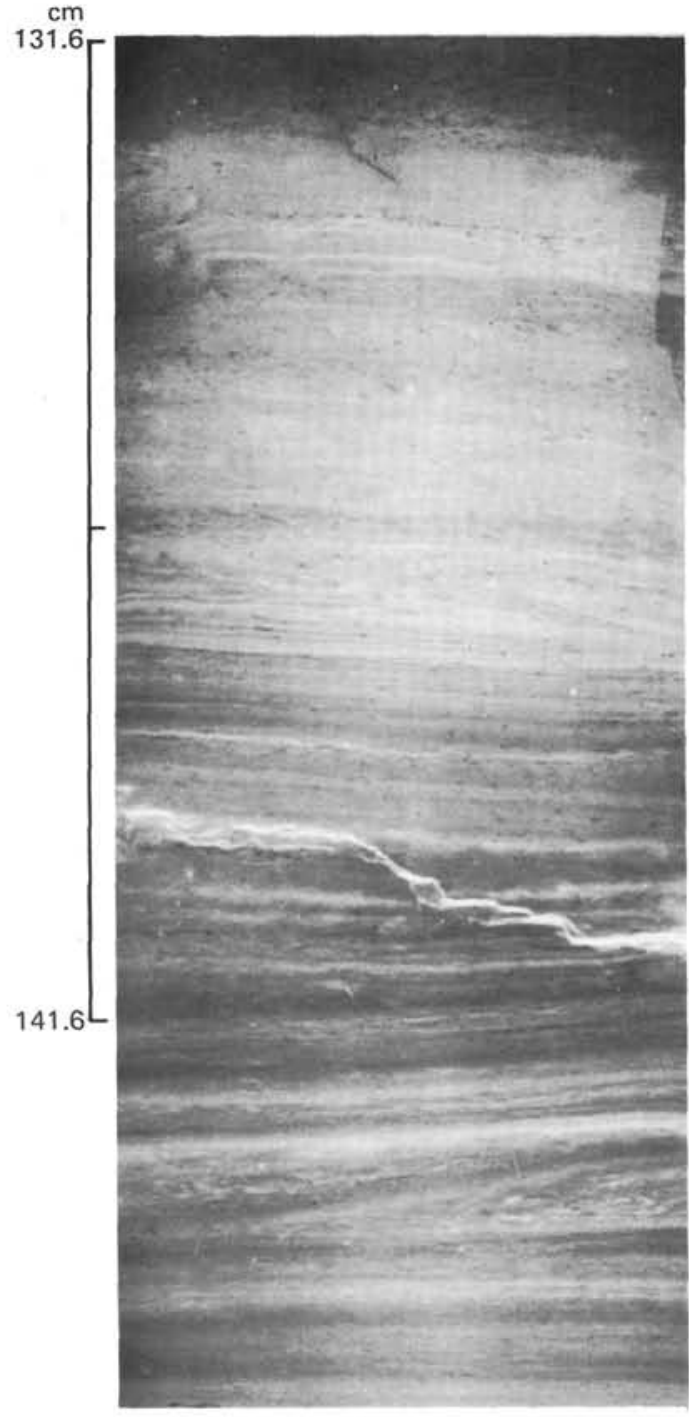

Figure 1F. Slab radiograph, 480-5-2, 131.6-145.5 cm. Layered: $134-136.5 \mathrm{~cm}$. Faint laminae: $137.7-145.5$ $\mathrm{cm}$. 


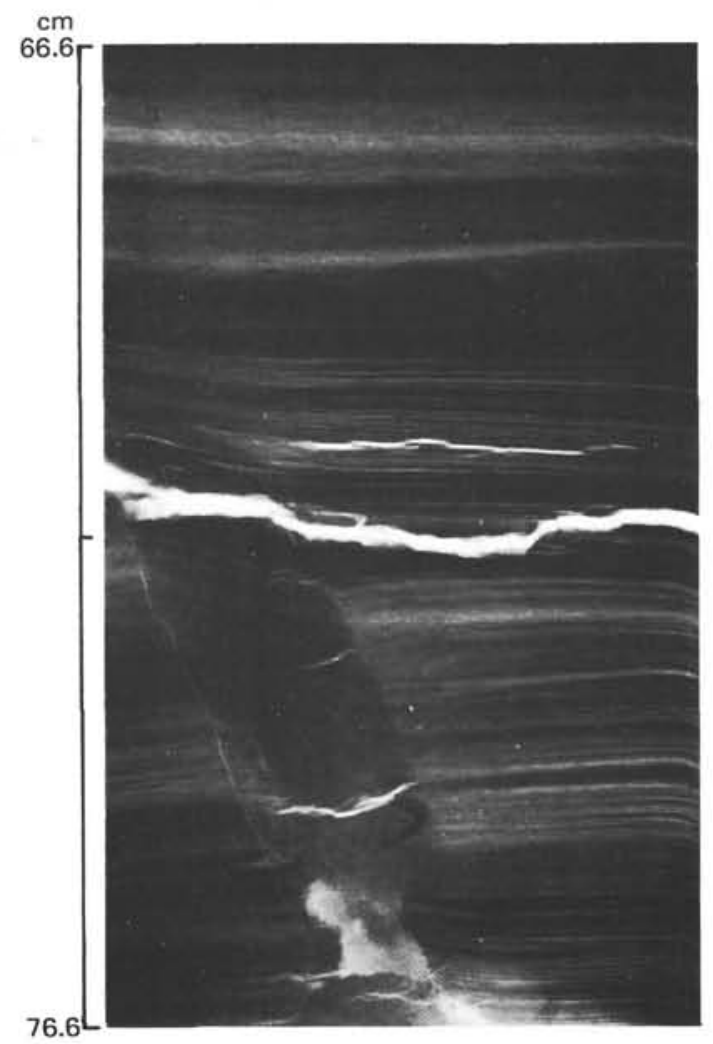

Figure 1G. Slab radiograph, 480-14-1, 66.6-76.6 cm. Burrow: Perhaps the best definition of burrow structures is in the context of laminated sediments. The tures is in the context of laminated sediments. The burrow is thinner than the slab as evidenced by the muted but continuous laminae in the burrow region.

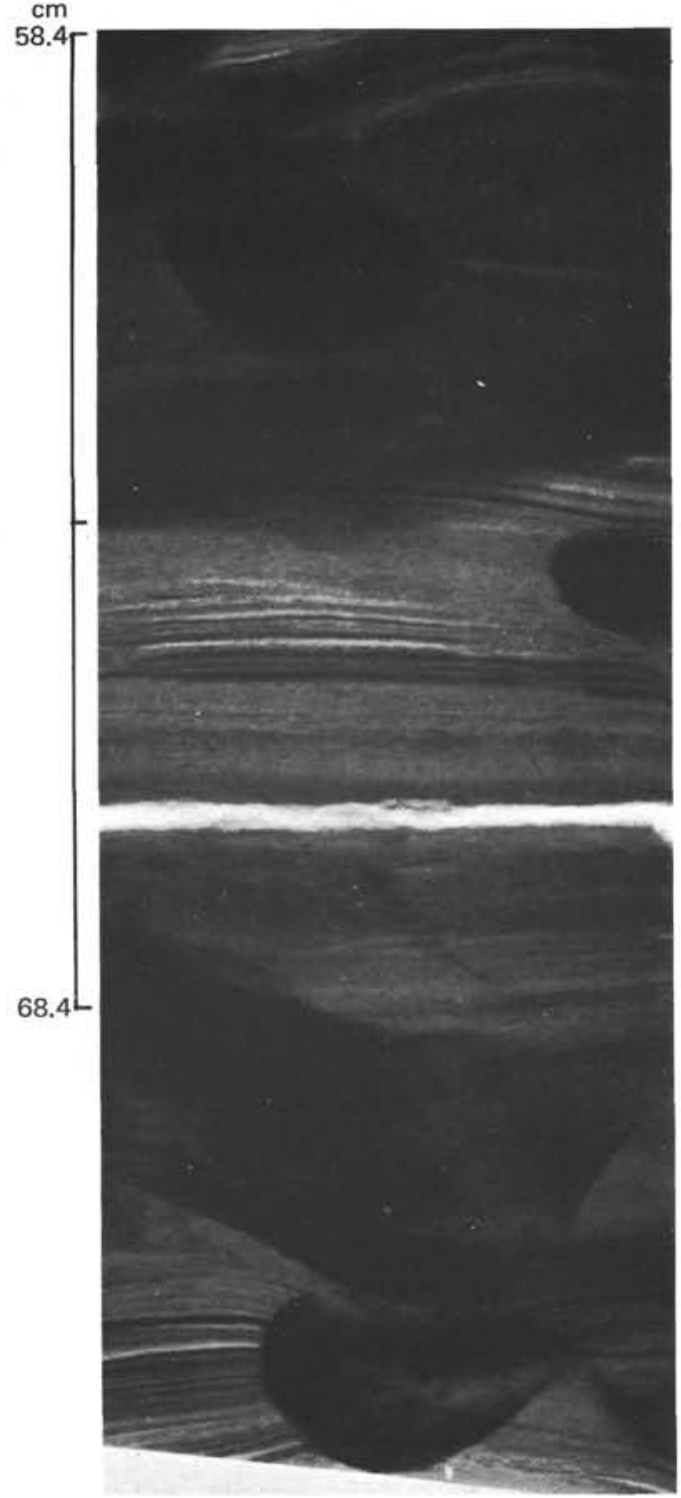

Figure $1 \mathrm{H}$. Slab radiograph, 480-6-2, 54.4-72.8 cm. Burrow: Increasing burrow occurrence progressively destroys the original laminations.

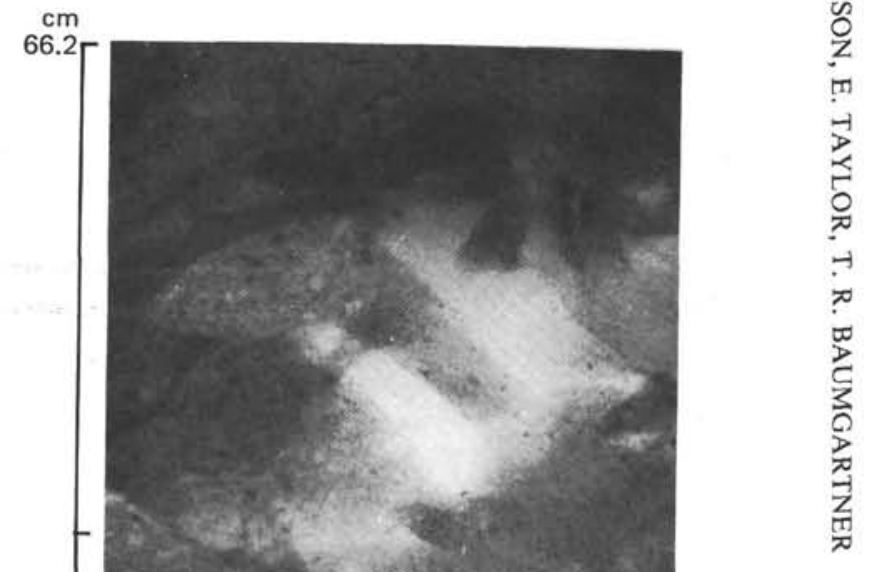

Figure 1I. Slab radiograph, 480-8-2, 66.2-78.5 cm Mottled: As burrowing progresses, no original structure remains. This radiograph is part of a sequence indicating that the original deposition was lami-
nated but was subsequently biologically disturbed. 


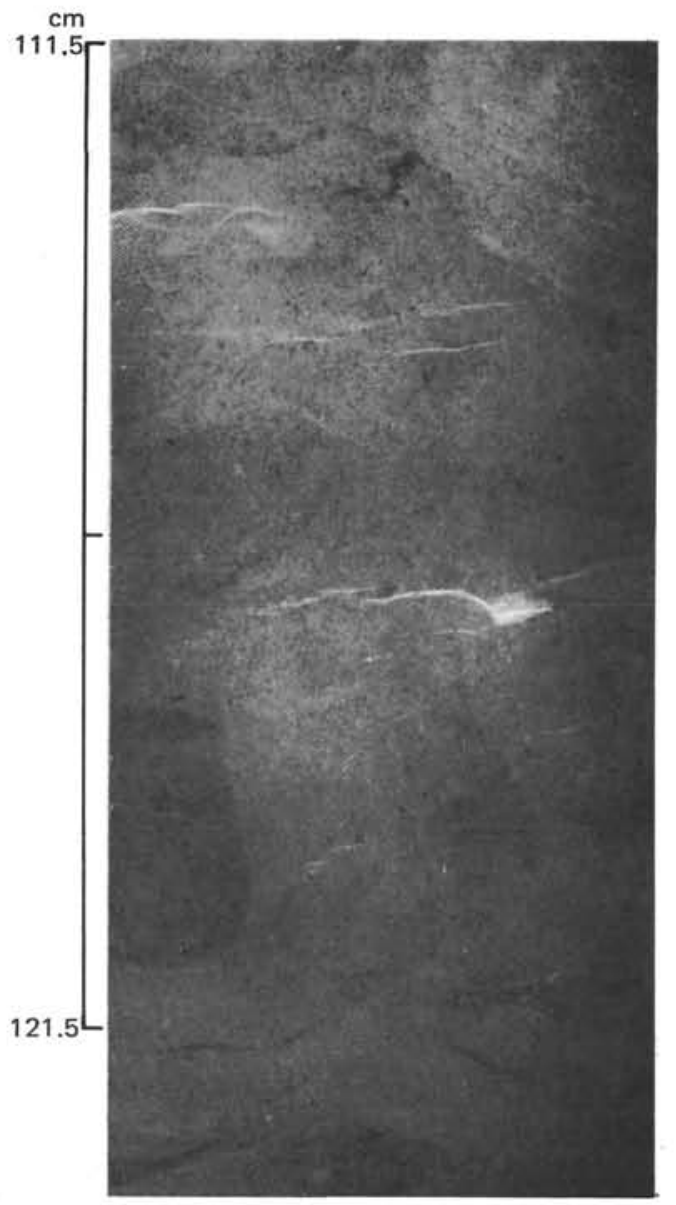

Figure 1J. Slab radiograph, 480-4-3, 111.5-123.3 cm. Faintly mottled: Burrow structures, though present, are much less distinct than in the previous figure. in this case there is no indication that the sediment was originally layered.

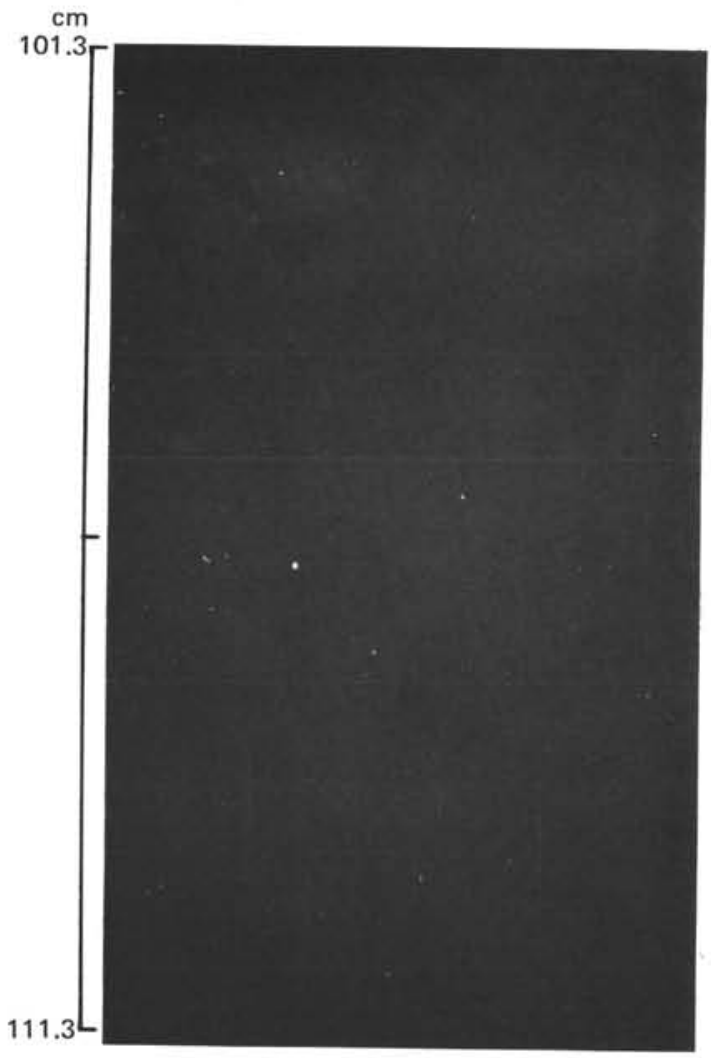

Figure 1K. Slab radiograph, 480-6-1, 101.3-111.3 cm. Homogeneous: The extreme result of burrowing is the production of sediment with essentially no lateral or vertical variation in density. Presumably, disturbance of this sediment began at the time of deposition.

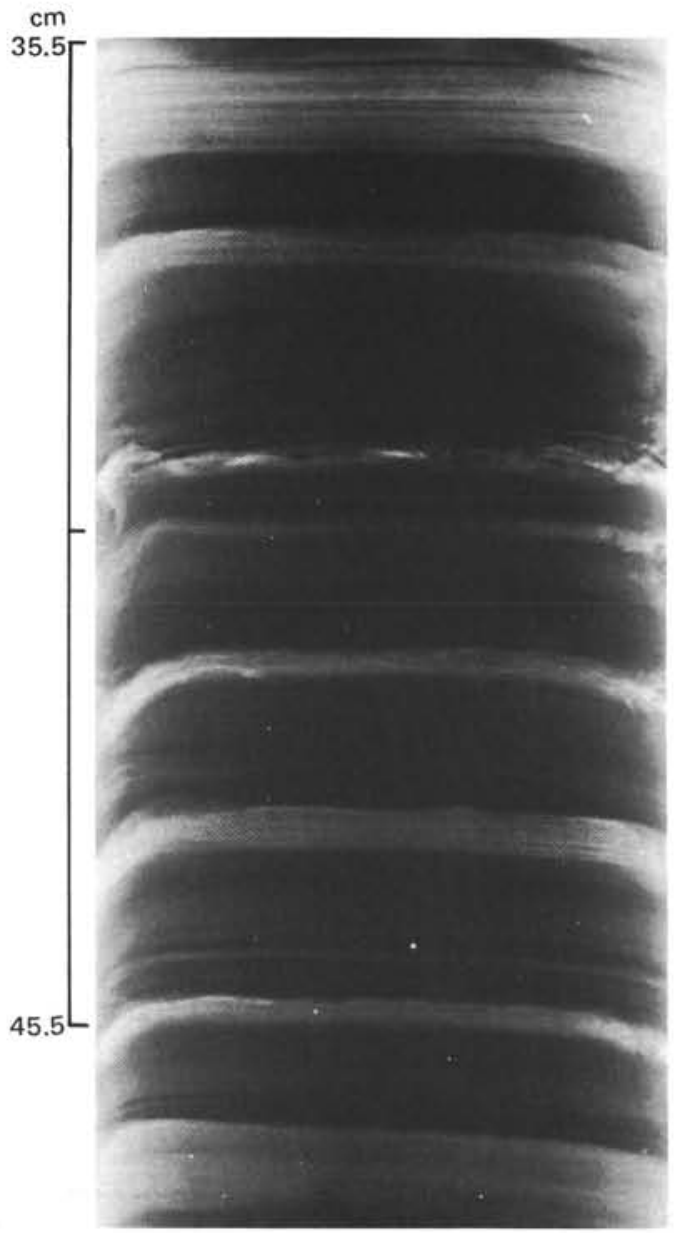

Figure 1L. Halfcore radiograph, 480-21-2, 35.5-47.6 $\mathrm{cm}$. Gray layer: The darker bands are gray layers with internal layering. Note the extremely thin laminations in the regular sediment deposition. 


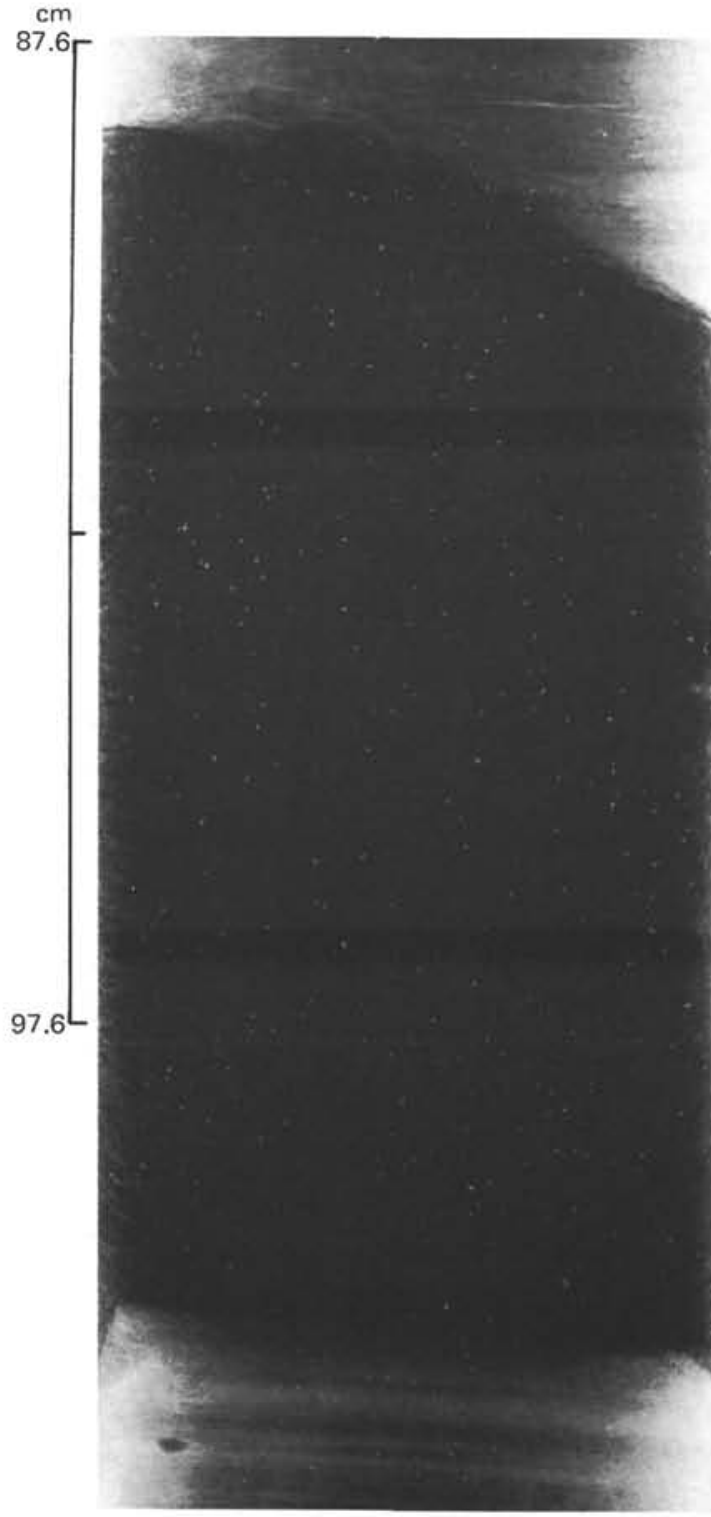

Figure 1M. Halfcore radiograph, 480-20-1, 87.7-102.7 cm. Sand: recovered.
Greenland Ice Core $\delta 0^{18}$ Chronology (after Dansgaard et al., 1971)

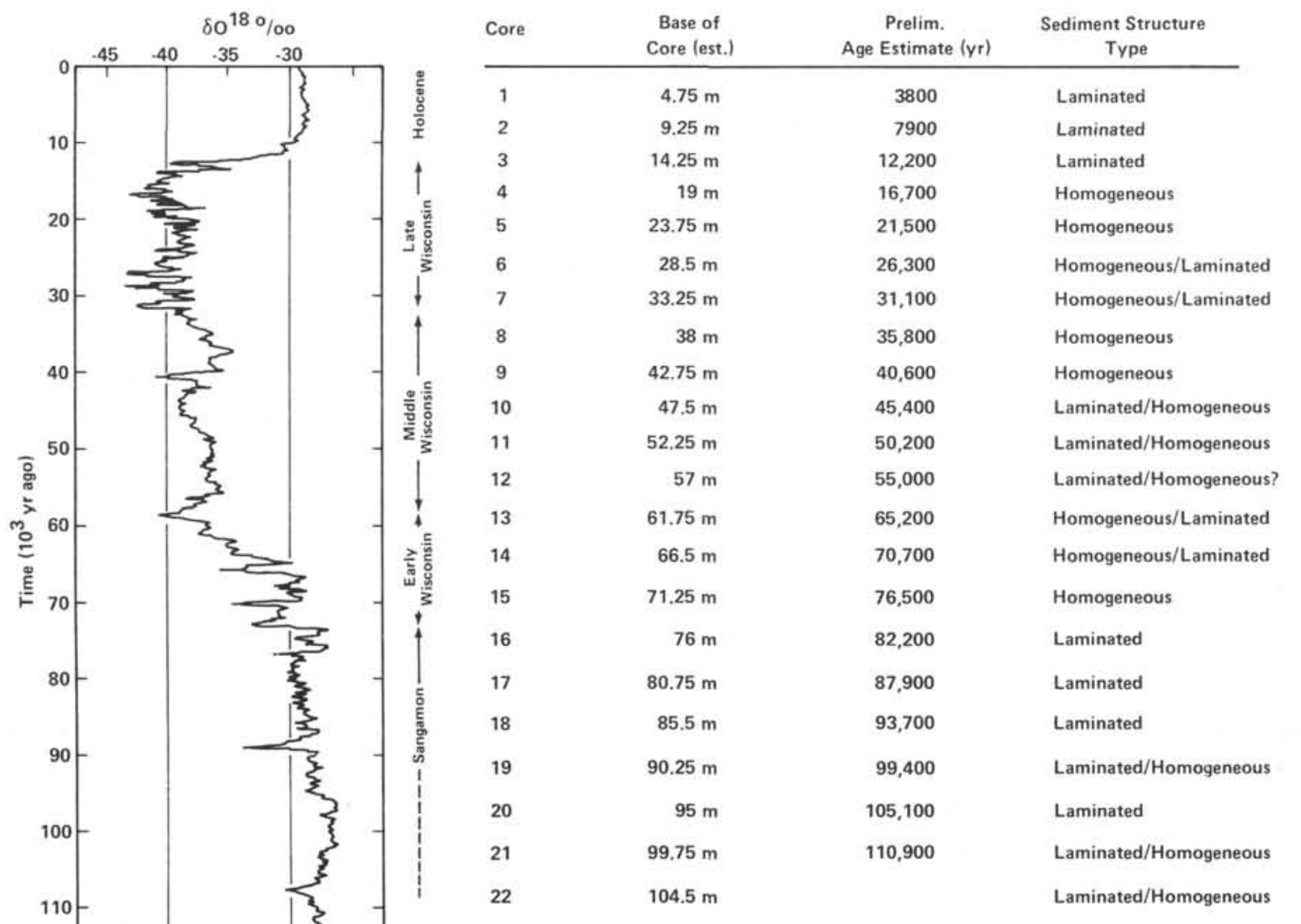

Figure 2. Preliminary age estimates for the bases of Cores 1 through 22 are tabulated along with the stratigraphy of sediment structure types. Comparison of this preliminary chronology for Core 480 to the Greenland ice core chronology based on $\delta 0^{18}$ variation (Dansgaard, et al., 1971) indicates that the interglacial intervals are represented by predominantly laminated sediments; glacial intervals are represented by predominantly homogenous sediments. 